\title{
Research on the Cultivation Education of Socialist Core Values of Art Students
}

\author{
Zhonghao $\mathrm{Hu}^{1}$, Lin Luo ${ }^{2}$ \\ ${ }^{1}$ Chengdu University, Chengdu, Sichuan, 610106 \\ ${ }^{2}$ Sichuan Technology and Business University, Chengdu, Sichuan, 610106
}

Keywords: cultivation education; socialist core values

\begin{abstract}
In recent years, our country has gone farther and farther along the road of quality education reform. Many experts believe that higher education in our country should further strengthen the cultivation of students under the guidance of the scientific education concept. The 18th Party Congress has put the core values of practicing socialism on the agenda. Higher education has made important contributions to the education and cultivation of China's human resources. Therefore, China needs to match the development of higher education with the present era spirit and the pace of China's social development, which is a very necessary and urgent task.
\end{abstract}

\section{Introduction}

In our social value system, the core values of socialism have always occupied the core position. On the one hand, its content is the embodiment of the characteristics of the core value system of the social subject. On the other hand, it is also the embodiment of the connotation requirements of the core value system of the social subject. It is the essence of the core content of the core social value system. In all stages of China's education system, higher education is one of the main channels for the cultivation of talents in China. In education and teaching, we can actually see the shadow of socialist core values from time to time in our usual teaching. Although only including the strong, harmonious, free, equality and other short 24 words. However, we all need to explore our own ways in continuous practice, integrate the core values into the daily teaching, integrate into the campus culture and integrate into student management. In view of this, the following will combine the connotation of the core value of socialism, respectively explain the "student self-management ability", "students autonomous inquiry habits", "students own moral improvement" and other student development education strategies.

\section{Student Self-inquiry Habits Education}

Socialist core values, advocacy of democracy, equality, and freedom. To effectively improve the effectiveness of higher vocational teaching activities, we should respect the subjectivity of students, flexibly use various forms of teaching methods, and establish a teaching platform to dig out the value of teaching materials and guide students' autonomy. Participation, self-inquiry, self-directed learning, and active cooperation have become participants, promoters, and practitioners of teaching activities, so as to comprehensively improve teaching efficiency and nurture and practice socialist core values.

As stated above, in the perspective of socialist core values, we should actively cultivate students' self-inquiring habits. First of all, we need to sort out the principle of autonomous participation. First of all, we need to understand exactly what is autonomy. On a theoretical level, so-called autonomous participation refers to autonomous learning and inquiry. Self-directed learning means that students adjust and follow up autonomously according to their own learning conditions. Autonomous inquiry refers to the student's ability to discover something new through his own thinking. We can see that the protagonist of self-involvement is a student. Therefore, we should fully mobilize the enthusiasm of students' themes during the teaching process so that they can participate more actively in the activities. This means that the current higher educationshould cultivate students' spirit and ability to participate autonomously on the basis of arousing students' 
interest in learning, which mainly includes both hands-on and creative abilities. The so-called burden-reduction education is to allow students to truly participate in the initiative.

In the previous higher vocational teaching model, students often only passively absorbed the knowledge of teachers and professors in the classroom, and needed to complete a large number of overloaded assignments outside of class. This is why so many students complained that they did not explore and innovate. The reason is. Under the current new model of higher education, teachers should give more time to study. Of course, we also need to apply this principle in accordance with the principle of teaching students according to their aptitude. For students whose basics are not very good, we should urge them to practice more. For students with a better foundation, we should give them time to study on their own. A lot of mechanized exercises will not only make them improve themselves well, but also delay them. Their study time. This is the true meaning of reducing the burden on students.

\section{Ways of Organic Combination of Cultivating Education and Socialist Core Values Education}

Based on the relationship between the two, it is clear that in the process of ideological and political education, we must adhere to the principle of people-oriented, pay attention to differences and levels, focus on practical education, use the socialist core values as the guideline, and cultivate education as the starting point. The mutual promotion of the two.

When educating students, they focus on integrating the country's needs for college students' needs and their own growth. The starting point is the growth needs of students and the requirements for related abilities in growth needs are integrated into the ultimate goal of fostering education.

In the work, it is found that for students with strong daily normative behaviors, most of their values are consistent with the socialist core values. That is to say, students' daily behavior is the external manifestation of their values. Based on this, students are divided into Different levels, guide education. For special students, we must not only strengthen education and guidance, but also give them more care and create more positive and positive life experiences.

In order to better allow students to internalize socialist core values and improve their basic qualities, in the process of education, a single form of education has been transformed into a participatory teaching style that focuses on students. Education in the form of situational education, experiential education, and game education are used to stimulate students' interest in learning and guide students to think positively, experience feelings, and transform the ideological content of education into their own beliefs and behavioral qualities.

Most college students nowadays are only children. They have obtained more and paid less on the road to growth. Some students regard the care given by their parents and others as a matter of course. In addition, most of their energy in the process of their growth is spent on learning. Their interpersonal skills are poor, and their self-evaluation is not comprehensive and accurate. Under this premise, social activities and public-welfare-related activities for college students should not only help college students understand the society and integrate into the society, they should also cultivate their enthusiasm for public services, and they can also allow them to reap greater spiritual wealth through service and dedication. Increase personal satisfaction and sense of well-being, and in the enhancement of interpersonal skills, correctly understand the self and enhance the individual's overall quality. Actively guiding university students to participate in public welfare undertakings is also a concrete embodiment of practicing the core values of socialism. It also has a significant role in promoting a civilized and harmonious social environment.

In the era of big data, the ideological and political education team must constantly improve the media literacy and synchronize with the national education modernization achieved by 2020. At present, only efforts to reform and innovate, combined with their own practical experience to absorb "adoption of lessons" and "flip the classroom" and other advanced experience in order to keep up with the pace of the times, in order to improve the quality of ideological and political education and effective action, and promote the early realization of the modernization of higher education. The new online media is rapidly changing students' learning methods, working methods and lifestyles. It 
is an important front for cultivating and practicing the core values of socialism. We must adapt to the complex and intensive new situation in the ideological field, strengthen the position awareness, and increase occupation. Positional skills. To this end, we must strengthen the training of the entire network of ideological and political education personnel. Now all instructors, training and research bases have put the use of online new media in ideological and political education into their training content, and they have also conducted skill competitions; some universities have already started "weibo training classes" and "wechat training classes" very early. On the one hand, we must build a high-quality network of thought and political work teams, and on the other hand, we must do a good job of all staff training. In this regard, we must also follow the frontiers and pay attention to the progress made by the National Education Informatization Center of the Ministry of Education and the Education Informatization Centers of the provinces on the development of education informatization. In particular, we must learn advanced experience to promote the modernization of ideological and political education, such as the Cyber Information Center of Peking University. The East China Normal University's "MuChun Research Center" is at the forefront of education informatization. Not long ago, The Ideological and Theoretical Education Guide published the most influential teacher activities in the selection of ideological and political theory classes. Fudan University, Renmin University of China and other schools introduced "Music Lessons" and "Flip the Classroom" to "Ideological and Moral Education". The "Reform and Law Basics" course enables students to self-study their own time and self-study through open online learning and high-quality teaching resources. On this basis, offline class discussions, teacher-student interactions or project-specific assignments by project, in-depth topics, and student interaction. As a result of its flexible approach, it mobilized the initiative of students, demonstrated their ability to teach students according to their aptitude, and shared high-quality educational resources. Therefore, it was welcomed and praised by students and greatly improved the effectiveness of education. Should take measures to promote. The second is that teachers and political cadres must "online the Internet" on the basis of improving media literacy. They should not only discover and support the "opinion leaders" among students, but also should become "opinion leaders" and "leaders". Take WeChat as an example. Like all media networks, all thoughts are diverse, diverse, and changeable, among which the denial of party leadership, the vilification of the party to demonize socialism, distorting history, and opposing ministries of Marxism appear from time to time. We must have a sense of urgency and awareness of crisis, be a good opinion leader, spread positive energy in WeChat, and direct the lyrical orientation of WeChat's circle of friends. We must not ignore the content of denying the Party, negating socialism, and negating Marxism, and blaming political rumors. The verified important information should not be blindly liked or blindly changed, and should not be reported for low-level, lyrical, and yellow content. Third, we must combine with computer software professionals to develop or use software that analyzes big data in students' minds, and sort and organize them in a timely manner to provide relevant departments with initiatives to improve their work, guide social thoughts in a timely manner, guide public opinion, and solve problems in the bud. Not yet.

The cultivation of socialist core values must be penetrated into all aspects and the entire process of institutional construction. Adhere to the socialist core values to lead the construction of the legal system and the construction of various rules and regulations, so that all laws, regulations, and institutional guidelines are based on socialist core values as their soul and reflect their requirements. We must govern the country in accordance with the law, strictly implement the constitution and various laws, and strictly implement all rules and regulations. Since the system is more fundamental, long-term, stable, and continuous, strict implementation of the various rules and regulations will become an important way and a good vehicle for education. The core values of socialism must be cultivated in practice. Teaching is for not teaching. Education and training can only be implemented through guidance and practice. As time passes by, educated people can consciously practice and enhance their self-education and self-management capabilities, so as to achieve the goal of fostering socialist core values. Therefore, from the fundamental point of view, the cultivation education of the core values of socialism must pay attention to the practice and educating people, infiltrating the 
cultivation of socialist core values into people's practical activities such as study, work, life, and management. The long-term mechanism of cultural people.

\section{Conclusion}

To build a long-term mechanism for fostering socialist core values and fostering education, our ideological and political education will not only better guide people to develop and uphold the core values of socialism, form excellent moral character, but also better realize the "consolidation of Marxism in consciousness". The basic task of guiding the status in the field of morphology and consolidating the common ideological foundation of the great solidarity of the people of all nationalities across the country.

\section{References}

[1] Chen Lan. University Students Society Core Values Outlook Education Exploration [J]. Gao et al. Architectural Education, 2010, 19(4):28.

[2] Tang Xuelian, Yue Baibing. Under the new media environment, college students socialist core values develop education [J]. Theoretical perspective, 2014 (6).

[3] Tao Shaoxing, Zhu Fenhua, Ji Hongliang. Exploration of the cultivation path of college students' socialist core values under the new media environment [J]. Journal of Social Science of Jiamusi University, 2014, 32 (5): 81 - 84.

[4] Cheng Yuzhong. A Probe into the Internalization Mechanism and Externalization of College Students' Socialist Core Values[J]. College Instructors, 2015(2). 